\title{
Introdução ao Direito Ambiental Brasileiro ${ }^{1}$
}

\author{
Antônio Herman V. Benjamin²
}

Quinto país em extensão territorial ${ }^{3}$, o Brasil tem $1,7 \%$ da superfície da terra (5,7\% das áreas emersas) e 47,3\% da América do Sul. Sua população é a sexta do mundo, com mais 160 milhöes de habitantes. Some-se a esses dados superlativos a riqueza do seu patrimônio natural e configurado está um país que, compreensivelmente, ocupa posição central nas discussões sobre a sustentabilidade do planeta.

Visto sob todos os ângulos de sua estrutura econômico, cultural e jurídico, - Brasil ainda dá os primeiros passos na busca da compatibilização entre crescimento econômico e proteção do meio ambiente. Nossos 500 anos de história estão marcados a ferro (primeiro, o machado, depois, os tratores e motosserras) e fogo (as queimadas e, mais recentemente, as chaminés descontroladas). Durante todo esse período, a natureza-inimiga, como visão distorcida, comandou nossas ações.

Em nada diferindo de outras nações, algumas hoje as mais ricas do mundo, alavancamos o progresso convencidos de que para crescer era preciso destruir. Aceitávamos, sem questionamento, que nossa caminhada rumo ao bem-estar social dependia da dominação e exclusão da natureza. E assim se foram as florestas, os rios, a costa litorânea, a qualidade do ar, a fertilidade do solo e a pureza do subsolo.

Náo carece ser romântico para reconhecer que somos todos herdeiros e vítimas dessa percepção simplista das relações homem-natureza que, casada com o perverso desequilíbrio social, com ilhas de riqueza pontilhando sobre un mar de pobreza, haveria que redundar na gravidade e larga escala dos nossos problemas

\footnotetext{
${ }^{1}$ Estudo apresentado, originalmente, no Fórum Lusófono sobre Redação Normativa e Direito do Ambiente, Praia, Cabo Verde, 23-27 de novembro de 1.998, sob os auspicios da IUCN e de sua Comissão de Direito Ambiental. O autor quer registrar seu mais sincero agradecimento a Mauricio Cysne pelo convite e organização impecável do evento.

2 Membro de carreira do Ministério Público do Estado de São Paulo, onde coordena as Promotorias de Justiça do Meio Ambiente. Presidente do Instituto "O Direilo por um Planeta Verde" e da Brazil U.S. Law Society. Professor de Direito Ambiental Comparado das Universidades do Texas (Austin) e llinois (Champaign-Urbana). Um dos redatores do Código de Defesa do Consumidor (1.990), da Lei da Improbidade Administrativa (1.991), da Lei da Concorrência (1.994) e da Lei dos Crimes contra o Ambiente (1.998).
}

${ }^{3}$ Săo $8.511 .996 .3 \mathrm{~km} 2$. 
ambientais atuais. Não estamos, pois, diante de efeitos nefastos atrelados tão-só às geraçōes da sociedade industrial, que, sem dúvida, deram novo e acelerado fôlego à trajetória centenária do assalto aos ecossistemas.

Muito ao contrário, há aqui um claro exemplo de degradaçăo intergeracional, onde os ataques ao meio ambiente perpetrados pela geração seguinte fazem-se por continuidade e adiçāo, uma pedra a mais nos estragos imputados a todos aqueles que a antecederam, num processo ininterrupto de cinco séculos. Ambientalmente falando, não temos muito o que festejar no passado, pois a história brasileira é uma coletânea de episódios, alguns até celebrados em tom épico, onde o homem é o conquistador e a natureza, a vítima. O que assistimos e criticamos hoje não é lá diferente do manequim-padrão da nossa evolução histórico-social.

$\mathrm{Na}$ ótica internacional, chama a atenção a destruição acelerada e comprovada da floresta tropical que cobre a bacia do rio Amazonas (floresta latifoliada equatorial). Infelizmente, a crise ambiental por que passa o país não se resume, nem geográlica, nem qualitativamente, à Amazônia. Mais impiedosa, extensa e irrecuperável tem sido a derrubada da Mata Atlântica e do Cerrado, ecossistemas extremamente ricos em diversidade biológica. No outro extremo da problemática, a poluição do ar, solo e águas põe em risco a saúde de milhóes de brasileiros e ameaça processos ecológicos endêmicos e vitais.

Essa lamentável constatação - uma nação formada às custas de gigantescos e irreversíveis danos aos ecossistemas nacionais - nāo nos pode levar ao pensamento utópico de que, adequadamente protegido, o meio ambiente seria hoje aquele mesmo que Pedro Álvares Cabral encontrou à época do descobrimento (rectius, conquista), em 1500. A natureza, sabe-se, é permanentemente transformada, tanto por sua próprias forças, como pela atuação do homem, ambas ocorrências arredias a controle absoluto.

Desses fatores, tirante catástrofes naturais infreqüentes, é a ação humana a que maiores e mais generalizados impactos traz, modificando por inteiro a face do planeta, alterando o meio físico e químico, extirpando e transformando ecossistemas inteiros, apagando espécies e florestas, e poluindo o ar, solo e águas com substâncias tóxicas e perigosas.

Ainda não fomos capazes de identificar ou pôr em prática métodos adequados para resolver os fenômenos naturais ou humanos que alteram o equilibrio dinâmico do nosso planeta. Continuamos à procura de soluçóes eficientes, no terreno da ciência e, naquilo que nos interessa nesses trabalho, na esfera juridica. Para o desespero e insatisfação de muitos, essas duas categorias de forças, no estágio atual do conhecimento científico e do planejamento, lá permanecem como vetores de impossível estancamento, passíveis somente de mitigação, sempre insuficiente.

Isso equivale dizer que, por maiores e mais ágeis que sejam nossos esforços, a proteção ambiental, principalmente aquela traçada em normas jurídicas, está condenada, pelo menos por enquanto, a uma existência imperfeita, conquanto 
marcada pela impotência - e com esta, pela insuficiência -, para garantir a incolumidade dos processos ecológicos.

Sem sequer tocar a superfície dessas questóes mais profundas do relacionamento homem-natureza, o presente trabalho, de forma simplificada, e por isso mesmo destituído de maiores pretensóes acadêmicas, propöe-se a dar uma visão panorâmica da proteção jurídica do ambiente no Brasil ${ }^{4}$.

\footnotetext{
${ }^{4}$ Já é vasta a doutrina brasileira de Direito Ambiental. Cf., em particular, Adalberto Carim Antonio, Evolução e Maturidade do Direito Ambiental Brasileiro, Manaus, Grafima, 1.992; Alvaro Valery Mirra, Impacto Ambiental: Aspecto da Legislaçăo Brasileira, São Paulo, Oliveira Mendes, 1.998; Ann Helen Wainer, Legislaçäo Ambiental Brasileira: Subsidios para a História do Direito Ambiental, Rio de Janeiro, Forense, 1.991; Antonio Carlos Brasil Pinto, Turismo e Meio Ambiente. Aspectos Jurídicos, Campinas, Papirus Editora, 1.998; Antōnio Herman V. Benjamin (coordenador), Dano Ambiental: Prevenção, Reparação e Repressão, São Pauło, Revista dos Tribunais, 1.993; Antônio Herman V. Benjamin, José Carlos Meloni Sicoli e Paulo Roberto Salvini, Manual Prático da Promotonia de Justiça do Meio Ambiente, São Paulo, Procuradoria-Geral da Justiça, 1.997; Celso Antonio Pacheco Florillo e Marcelo Abelha Rodrigues, São Paulo, Max Limonad, 1.997; Cristiane Derani, Direito Ambiental Econômico, São Paulo, Max Limonad, 1.997; Édis Milaré e Antônio Herman V. Benjamin, Estudo Prévio de Impacto Ambiental, São Paulo, Revista dos Tribunais, 1.993; Édis Milaré, Curadoria do Meio-Ambiente, São Paulo. Associação Paulista do Ministério Público, 1.988; - - A Ação Civil Pública na Nova Ordem Constitucional, São Paulo, Saraiva, 1.990; Fábjo Nusdeo, Desenvolvimento e Ecologia, São Paulo, Saraiva, 1.975: Franciso José Marques Sampaio, Meio Ambiente no Direito Brasileiro Atual, Curitiba, Juruá, 1.993; - - Responsabilidade Civit e Reparação de Danos ao Meio Ambiente, 2a edição, Rio de Janeiro, Lumen Juris, 1.998; Guido Fernando Silva Soares, As Responsabilidades no Direito Internacional do Meio Ambiente, Campinas, Komedi Editores, 1.995; Ivete Senise Ferreira, Tutela Penal do Patrimônio Cultural, São Paulo, Revista dos Tribunais, 1.995; José Afonso da Silva, Direito Ambiental Constitucional, 2a edição, São Paulo, Malheiros, 1.995; Juraci Perez Magalhães, Recursos Naturais, Meio Ambiente e sua Defesa no Direito Brasileiro, Rio de Janeiro, Editora da Fundaçăo Getúlio Vargas, 1.982; Marcelo Gomes de Souza, Direito Minerário e Meio Ambiente, Belo Horizonte, Del Rey, 1.995; Paulo Affonso Leme Machado, Direito Ambiental Brasileiro, 7a edição, São Palilo, Malhereios, 1.998; _ _ Estudos de Direito Ambiental, São Paulo, Malheiros, 1.994; Paulo José da Costa Júnior, Direito Penal Ecológico, Rio de Janeiro, Forense Universitária, 1.996; Paulo Roberto Pereira de Souza e Jon Mills, Conflitos Jurídicos, Econômicos e Ambientais, Maringá, Editora da Universidade Estadual de Maringá, 1.995; Roberto Armando Ramos Aguiar, Direito do Melo Ambiente e Participação Popular, Brasilia, Ministério do Meio Ambiente e da Amazônia Legal, 1.994; Vladimir Passos de Freitas, Direito Administrativo e Meio Ambiente, 2a ediçäo, Curitiba, Juruà, 1.998; __ coordenador, Direito Ambiental em Evolução, Curitiba, Juruá, 1.998; Vladimir Passos de Freitas e Gliberto Passos de Freitas, Crimes contra a Natureza, $5 a$ edição, São Pauto, Revista dos Tribunais, 1.997.

De consulta obrigatória, ainda, a Revista de Direito Ambiental, publicada pela Editora Revista dos Tribunais; veja-se, também, a Revista dos Mestrandos em Direito Econômico da UFBA, Edição Especial: Direito Ambiental, coordenaçăo de Kadja Maria Ribeiro Parente e Sergio Novais Dias, Salvador, Universidade Federal da Bahia, jan./1.996-dez./1.997.
} 


\section{EVOLUÇÃO HISTÓRICA DA PROTEÇÃO JURÍDICA DO AMBIENTE}

Retrospectivamente e em favor da clareza didática, podemos identificar três regimes (mais modelos do que propriamente períodos estanques) na evolução legislativo-ambiental brasileira. Não se tratam de fases históricas critalinas, apartadas, delimitadas e mutuamente excludentes. Temos, em verdade, valorações ético-jurídicas do ambiente que, embora perceptivelmente diferenciadas na forma de entender e tratar a degradação ambiental e a própria natureza, são, no plano temporal, indissociáveis, já que funcionam por combinação e sobreposição parcial, em vez de por integral reorganização ou substituição. São estilos legislativos que encontram na interpenetração sua marca, desenhando modelos legais que convivem, lado a lado - o que não quer dizer harmonicamente -, não obstante suas diversas filiaçóes históricas ou filosóficas, o que, em certa medida, amplia a complexidade da interpretação e implementação dos textos normativos em vigor.

Do descobrimento em 1500 até aproximadamente o início da segunda metade do século XX, pouca atenção recebeu a proteção ambiental no Brasil, à exceção de umas poucas normas isoladas que não visavam, na vocação principal, resguardar o meio ambiente como tal. Seus objetivos eram mais estreitos. Ora almejavam assegurar a sobrevivência de alguns recursos naturais preciosos em acelerado processo de exaurimento (o pau-brasil, p. ex.), ora, em outro plano, colimavam resguardar a saúde, valor fundamental este que ensejou, não só entre nós, algumas das mais antigas manifestações legislativas de tutela indireta da natureza 5.

Inicialmente, a questão ambiental, no período colonial, imperial e republicano, este até a década de 60 do atual século, juridicamente não existia, caracterizadas as iniciativas pontuais e raras do Poder Público mais como conservação do que propriamente como preservação. Esta, pois, a fase da exploraçāo desregrada ou do laissez-faire ambiental, onde a conquista de novas fronterras (agrícolas, pecuárias e minerárias) era tudo que importava na relação homemnatureza. Tinha na omissão legislativa seu traço preponderante, relegando-se eventuais conflitos de cunho ambiental quando muito ao sabor do tratamento pulverizado, assistemático e privatístico dos direitos de vizinhança.

Num segundo momento, a fase fragmentária, o legislador - agora já preocupado com largas categorias de recursos naturais mas ainda não com o meio ambiente em si mesmo considerado - impôs controles legais às atividades exploratórias. A recepção incipiente da degradação do meio ambiente pelo ordenamento operava, no plano ético, pelo utilitarismo (tutelando somente aquilo que tivesse interesse economico) e, no terreno formal, pela reducionismo, tanto

${ }^{5}$ Cf. Antỏnio Herman V. Benjamin, Objectivos do Direito Ambiental, in Actas do / Congresso Internacional de Direito do Ambiente da Universidade Lusiada - Porto, Coordenação de Branca Martins da Cruz, 23-25 de novembro de 1.995, Porto, 1996, p. 25. 
do objeto (o fatiamento do meio ambiente, a ele ainda se negando, holisticamente, uma identidade jurídica própria), como, até em consequência, do aparato legislativo. Encaixam-se aí o Código Florestal ${ }^{6}$, de 1965; os Códigos de Caça ${ }^{7}$, de $\mathrm{Pesca}^{8}$ e de Mineração ${ }^{9}$, todos de 1967; a Lei da Responsabilidade por Danos Nucleares ${ }^{10}$, de 1977; a Lei do Zoneamento Industrial nas Áreas Críticas de Poluição", de 1980 (embora traga ela elementos próprios da terceira fase); e a Lei de Agrotóxicos ${ }^{12}$, de 1989.

Ainda nesse período, pelo Decreto Federal n. 73.030, de 30.10.73, foi criada a SEMA - Secretaria Especial do Meio Ambiente, subordinada ao Ministério do Interior, o que não deixa de ser curioso, já que temos aí um precendente em que a estrutura administrativa, mesmo que em caráter precursor, adianta-se ao quadro normativo especializado, que só apareceria mais adiante.

Finalmente, indicando uma (re)orientação radical de rumo, aparece a Lei da Política Nacional do Meio Ambiente (1981) ${ }^{13}$, dando início à fase holística, onde o ambiente passa a ser protegido de maneira integral, vale dizer, como sistema ecológico integrado (resguardam-se as partes a partir do todo), com autonomia valorativa (é, em si mesmo, bem jurídico) e com garantias de implementação (= facilitação do acesso à justiça). Só con a Lei n. 6938/81, portanto, é que verdadeiramente começa a proteção ambiental como tal no Brasil, indo o legislador além da tutela dispersa, que caracterizava o modelo fragmentário até então vigente (assegura-se o todo a partir das partes). Afastando-se da metodologia de seus antecessores legislativos ${ }^{14}$, a lei não só estabeleceu os princípios, objetivos e instrumentos da Política Nacional do Meio Ambiente, como ainda incorporou, de vez, no ordenamento jurídico brasileiro o Estudo de Impacto Ambiental, instituindo, ademais, um regime de responsabilidade civil objetiva para o dano ambiental, sem falar que the coube conferir ao Ministério Público, pela primeira vez, legitimação para agir nessa matéria ${ }^{15}$.

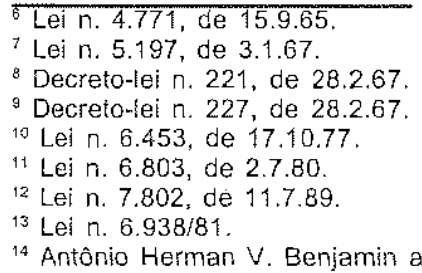
Heine, Mohan Prabhu and Anna Alvazzi del Frate (editors), Environmental Protection - Potentials and Limits of Criminal Justice: Evaluation of Legal Structures, Freiburg im Breisgau, UNICRI, 1.997, p. 133. 15 Como melhor veremos adiante, essa legitimação para agir fol, posteriormente ampliada pela Lei r. 7.347/85, permitindo-se que outros sujeitos, inclusive ONGs ambientais, pudessem propor ação civil pública visando a reconstituição do bem iesado ou indenizaçäo pelo dano causado. Cf., nesse ponto, Antonio Herman V. Benjamin, A insurreiçäo da aldeia global contra o processo civil clássico. Apontamentos sobre a opressão e a libertação judiciais do meio ambiente e do consumidor. in Édis Milaré (ed.), Ação Civil Pública (Lei no 7.347/85 - Reminiscências e Reflexões Após Dez Anos de Aplicação), São Paulo, Editora Revista dos Trbunais, 1.995, pp. 70-151. 
Com idêntica filiação holística e fechando o círculo da regulação legal (que agora é administrativa, civil e penal), é aprovada, em 1998, a Lei dos Crimes contra o Meio Ambiente ${ }^{16}$.

\section{PROTEÇÃO CONSTITUCIONAL DO AMBIENTE}

Só na década de 70 é que os sistemas constitucionais começaram a reconhecer o ambiente como valor a merecer tutela especiall?. Assim foi com as novas constituições dos países que saiam de um regime ditatorial, como, num primeira leva, Grécia, Portugal e Espanha, e posteriormente, numa segunda onda, o Brasil.

\section{Relevância da proteção constitucional do ambiente}

No terreno constitucional, uma pergunta inicial que se póe é a seguinte: seria a previsão da proteçã̃o do ambiente na constituição indispensável à atuação do legislador ordinário e do implementador (órgăos ambientais, juízes, Ministério Público e ONGs)?

A experiência comparada parece indicar que, embora não imprescindível, o reconhecimento constitucional expresso de direitos e deveres inerentes ao nosso relacionamento com o ambiente é, jurídica e praticamente, útil, devendo, portanto, ser estimulado e festejado.

No passado, antes mesmo do movimento de constitucionalização da proteção do ambiente, a inexistência de previsão constitucional inequívoca năo inibiu o legislador, aqui como lá fora, de promulgar leis e regulamentos que, de uma forma ou de outra, resguardavam os processos ecológicos e combatiam a poluição.

Ainda hoje, importantes sistemas jurídicos, aí incluindo-se os Estados Unidos, protegem o ambiente sem contar com apoio expresso ou direto na Constituição.

Não obstante essa constatação, razôes várias recomendam a constitucionalização do ambiente, podendo ser essa considerada uma tendência mundial, o que certamente foi percebido ao constituinte brasileiro de 1988.

\footnotetext{
10 Lel n. 9.605/98.

17 Cabe ressalvar que, de uma forma geral, todos os antigos paises comunistas do leste europeu previam, mas não implementavam, normas constitucionais vocacionadas à tutela do meio ambiente.
} 


\section{O meio ambiente no sistema constitucional brasileiro anterior a 1988}

Já notamos que a tutela legal do ambiente no Brasil tem início na década de 60 e consolida-se nos anos 80 e 90 . Quais os fundamentos constitucionais utilizados, à época, para justificar e legitimar tal intervençāo legislativa, se, como veremos, só a Constituição Federal de 1988 abrigou, expressamente, a proteção ambiental como direito e dever de todos?

A lacuna nas ordens constitucionais anteriores a 1988 năo foi sério óbice à regulamentação legal de controle das atividades nocivas ao ambiente. Faltando uma base incontroversa de apoio na Constituiçāo, o legislador ordinário fó buscar suporte ora na proteção da saúde (sob o argumento de que ela não pode ser assegurada em ambiente degradado), ora no regramento da produção e consumo ${ }^{18}$. Ou seja, degradação ambiental seria sinônimo de degradação sanitária, ou, pior, mero apêndice do universo maior da produção e do consumo. Uma argumentaçăo de cunho estritamente homocêntrica, com indisfarçável conteúdo economicista e utilitarista.

Naquele período, tal raciocínio vingou e serviu para dar sustentação à intervenção legislativa, recebendo, inclusive, respaldo judicial. Hoje, contudo, num juízo retrospectivo, bem podemos verificar o caráter limitado desse esforço, eticamente insuficiente e dogmaticamente frágil.

Eticamente insuficiente porque a tutela ambiental vem, lentamente, abandonando a rigidez de suas origens antropocêntricas, incorporando uma visão mais ampla, de caráter biocêntrico (ou mesmo ecocêntrico), ao propor-se a amparar a totalidade da vida e suas bases ${ }^{19}$.

Dogmaticamente frágil porque o direito à saúde não se confunde com o direito ao meio ambiente ecologicamente equilibrado: dividem uma ́rea de convergência (e até de sobreposição), mas os limites externos de seus círculos de configuração náo são, a rigor, coincidentes. Quase sempre quando se ampara o ambiente se está beneficiando a saúde humana. Sem dúvida, há aspectos da proteção ambiental que dizem respeito, de forma direta, à proteção sanitária. Assim é com o controle de substâncias perigosas e tóxicas, como os agrotóxicos; com a garantia da potabilidade da água e da respirabilidade do ar.

Mas, nem sempre é essa a hipótese. Inegavelmente, inúmeras vezes na intervenção do legislador ambiental, a saúde humana joga um papel secundário, periférico e até simbólico, como sucede com a proteção de certas espécies ameaçadas de extinção (o mico-leão dourado, p. ex.) ou de manguezais, no imaginário popular

${ }^{18}$ A Constituição de 1.969 previa, expressamente, a competência da União para legisiar sobre "defesa e proteção da saúde" (art. 8, inciso XVII, alínea c), in fine) e "produção e consumo" (art. 8, inciso XVIl, alínea d).

io A Constituição Federal de 1.988 refere-se à preservação e restauração de "processos ecológicos essenciais" (art. 225, par. 1 , inciso l); evidentemente, "essenciais" à sobrevivência do planeta, como o conhecemos, concepção que ultrapassa a fórmula tradicional da sobrevivência do homem. 
ainda vistos como mal-cheirosos e abrigo de mosquitos disseminadores de doenças. Em algumas situações - a proibição, p. ex., da caça de espécies peçonhentas ou perigosas aos seres humanos, como o jacaré e a onça - a determinação legal protetória chega mesmo a reduzir a segurança imediata das populaçôes que vivem nas imediaçôes do habitat desses animais.

\section{O meio ambiente na Constituiçáo Federal de 1988}

Esse quadro de omissão constitucional mudou inteiramente com a Constituição Federal de 1988, que tem todo um capítulo dedicado ao "meio ambiente", complementado por outros dispositivos esparsos que, de forma direta ou indireta, cuidam também da matéria.

A noma básica, de caráter fundamental, está posta no caput do art. 225: "Todos têm direito ao meio ambiente ecologicamente equilibrado, bem de uso comum do povo e essencial à qualidade de vida, impondo-se ao Poder Público e à coletividade o dever de defendê-lo e preservá-lo para as presentes e futuras gerações".

O art. 225, pela sua complexidade e feição revolucionária, merece estudo amplo e aprofundado. Na impossibilidade de fazê-lo aqui, vejamos alguns de seus aspectos mais salientes.

\section{Direito ao ambiente ecologicamente equilibrado}

Esse direito ao meio ambiente ecologicamente equilibrado tem como titulares, diz a norma, todos, vocábulo que, por náo estar, de forma clara, qualificado homocentricamente, pode referir-se tanto a todos os seres humanos como, numa perspectiva mais biocêntrica (e moderna), a todos os seres viwos. Se falta essa dimensão reducionista-antropocêntrica ao direito fundamental estatuído, metodologia diferente escolheu o legislador ao desenhar o rol dos deveres a ele correlatos, ou melhor, ao compor a figura dos sujeitos obrigados.

Da norma constitucional retira-se que são destinatários dos deveres associados a esse direito tanto o Poder Público, vale dizer, o Estado, como ainda a coletividade, ou seja, cada um dos seres humanos, individual e socialmente considerados.

\section{Função sócio-ambiental da propriedade}

O direito ao ambiente ecologicamente equilibrado não se encontra isolado no corpo constitucional. Não é norma solitária, perdida no oceano dos comandos da Constituição. Ao revés, é direito sintonizado e entrelaçado com outros institutos incorporados pelo constituinte. Un deles é a função social da propriedade, já reconhecida em constituições anteriores e que podemos denominar de "genérica", 
ponto de partida usado pelo regime de 1988 para inovar com a função sócio-ambiental da propriedade.

Já virou lugar comum apregoar-se que o direito de propriedade, nas ordens constitucionais modemas e democráticas, tem (ou deve ter) sempre um conteúdo social, que se expressa, em linguagem jurídica, pela fómula, universalmente adotada, da função social do domínio (e da posse). Um instituto gerido na conviçaão, hoje incontestável, de que a propriedade, mesmo quando privatizada em um dominus particular, deve operar, sem exceção, em favor do interesse coletivo.

O Brasil é pobre em estudos e aplicação efetiva da função social da propriedade. Aceito como abstração teórica, o instituto deixa de manifestar-se no cotidiano das relaçóes produtivas brasileiras e, a partir delas, no que mais nos importa, no conflito homem-natureza. No país, não é incomum que litígios ambientais, essa a desanimadora realidade, ainda sejam julgados sob os exclusivos auspícios do Código Civil, como se o princípio da função social da propriedade - para não falar da sua função sócio-ambiental - fosse fórmula alienígena ao ordenamento, devendo, por isso mesmo, ser afastada ou desconsiderada, no caso concreto.

Esse quadro de afastamento entre a teoria e prática talvez explique a insistência e até a forma pleonástica com que o constituite tratou a função social da propriedade, agregando-lhe, em vários pontos da Constituição, um conteúdo mais nítido e, a partir daí, espera-se, propiciando-lhe melhores oportunidades de implementaçăo.

$\mathrm{Na}$ Constituição de 1988, mais especificamente no contexto da propriedade rural, foi bem reduzida a ambiguidade conceitual que, até hoje, mantém como refém a noção geral de função social da propriedade, dificultando ou mesmo impedindo sua efetiva aplicação. Para a imensidão das áreas não-urbanizadas, a Constituição Federal incluiu, entre os pressupostos do cumprimento da função social genérica, a "utilização adequada dos recursos naturais disponíveis e preservação do meio ambiente" 20 . Repita-se, preservação do meio ambiente, noção mais rigorosa e protetória que conservação. Essa a base constitucional de onde extraímos o reconhecimento da função sócio-ambiental da propriedade e de institutos a ela correlatos.

É a adoção constitucional do princípio da função social da propriedade que legitima - mais, até exige - a intervenção do Poder Público, quando colima resguardar o "meio ambiente ecologicamente equilibrado" e os "processos ecológicos essenciais". Tais interferências legislativas, administrativas e judiciais bebem e alimentam-se na fonte do princípio geral.

Assim bem abrigadas no patamar mais elevado do ordenamento ( = a Constituição), essas atuações estatais, mais do que proibidas pelo legislador constitucional ou ensejadoras de desapropriação (direta ou indireta), configuram-se 
como dever-poder do Estado - e de cada cidadão, nos termos do art. 22521. Por isso mesmo, en regra desautorizam indenização, conquanto não se concebe seja o Poder Público levado a compensar por realizar tarefa que, por igual, nos termos da norma constitucional, é exigida do próprio particular, rol obrigacional esse instituído como pressuposto da garantia do direito de propriedade ${ }^{22}$.

\section{Caracterizaçâo dos direitos e deveres constitucionais}

No texto constitucional brasileiro, podemos identificar direitos e deveres ambientais explícitos e implicitos. São explícitos certos direitos incorporados, p. ex., no art. 225. São implícitos aqueles direitos constitucionalizados que, embora não cuidando de maneira exclusiva ou direta do ambiente, acessoriamente ou por interpretação terminam por assegurar valores ambientais (direito à vida ${ }^{23}$, direito à saúde ${ }^{24}$, direito de propriedade ${ }^{25}$, direito à informaçâa ${ }^{26}$, direitos dos povos indígenas ${ }^{27}$, direito ao exercício da ação popular ${ }^{28}$ e ação civil pública ${ }^{29}$, para citar uns poucos).

Num outro enfoque, na Constituição vamos localizar direitos ambientais materiais e outros que têm caráter total ou preponderantemente instrumental. Pertencem àquela categoria os direitos e obrigaçóes com claro conteúdo substancial, p. ex., o dever de "preservar e restaurar os processos ecológicos essenciais" 30 . Instrumentais são os que se prestam à execução ou implementaçăo dos direitos e obrigações materiais, alguns com feição estritamente ambiental (Estudo Prévio de Impacto Ambiental ${ }^{31}$ ), outros de aplicaçăo mais ampla, não restritos à área da tutela do ambiente (ação civil pública ${ }^{32}$, ação popular e inquérito civil).

\footnotetext{
${ }_{21}$ Repita-se, todos têm direito ao meio ambiente ecologicamente equilibrado, mas, em contrapartida, a Constituição impõe "ao Poder Público e à coletividade o dever de defendê-lo e preservá-lo para as presentes e futuras geraçōes" (art. 225, caput, grifei).

${ }^{22}$ No plano infraconstitucional, a Lei $n$. $6.938 / 81$ dispõe que "As atividades empresariais públicas ou privadas serão exercidas em consonância com as diretrizes da Política Nacional do Meio Ambiente" (art. 5, par. Ĺnico).

${ }_{23}$ Constituição Federal, art. 5, caput.

${ }^{24}$ Estabelece a Constituição que ao sistemá único de saúde, dentre outras atribuiçöes, compete "participar do controle e fiscalização da produçäo, transporte, guarda e utilização de substâncias e produtos psicoatjvos, tóxicos e radioativos" (art. 200 , inciso VIl, grifei), bem como "colaborar na proteção do meio ambiente, nele compreendido o do trabalho" (art. 200, inciso Vll, grifo meu).

${ }^{25}$ Constituiçäo Federal, art. 5, inciso XXIII, e art. 186, inciso II.

${ }^{26}$ Constituição Federal, art. 5, incisos XIV e XXXIII.

27 "São terras tradicionalmente ocupadas pelos indios as por eles habitadas em caráter permanente. as utilizadas para suas atividades produtivas, as imprescindiveis à preservaçăo dos recursos ambientais necessários a seu bem-estar e as necessárias a sua reprodução física e cultural, segundo seus usos, costumes e tradições" (Constituição Federal, art. 231, par. 1, grifei).

${ }^{28}$ Constituiçăo Federal, art. 5 , inciso LXXIII.

${ }^{29}$ Constituição Federal, art. 129, inciso III, e parágrafo 1.

${ }^{30}$ Constituição Federal, art. 225, par. 1 , inciso I.

${ }^{3 \dagger}$ Constitujção Federal, art. 225 , par. 1 , inciso IV.

${ }^{32}$ Constituição Federal, art. 129, inciso $I I I$ e par. 1.
} 


\section{Competências constitucionais}

$\mathrm{Na}$ Constituição Federal podemos identificar dois tipos de competências ambientais. Primeiro, as competências legislativas. Segundo, as competências de implementação.

A Constituição não deixa dúvida ao dispor que podem legisłar, em matéria de proteção do ambiente, a União, os Estados e o Distrito Federal. Esses entes políticos têm competência legislativa concorrente sobre "florestas, caça, pesca, fauna, conservação da natureza, defesa do solo e dos recursos naturais, proteção do meio ambiente e controle da poluição" "ె3, bem como sobre "responsabilidade por dano ao meio ambiente" 34 .

Na mesma linha, a Lei da Política Nacional do Meio Ambiente dispóe que "Os Estados, na esfera de suas competências e nas áreas de sua jurisdição, elaborarão normas supletivas e complementares e padrões relacionados com o meio ambiente, observados os que forem estabelecidos pelo CONAMA" ${ }^{\prime 35}$.

Constitucionalmente, os municípios, por sua vez, receberam autorização para "legislar sobre assuntos de interesse local" ${ }^{36}$ e "suplementar a legislação federal e a estadual no que couber" 3 . Vale dizer, detêm o poder de legistar em matéria ambiental, desde que se trate de matéria de caráter local ou, então, para complementar as normas jurídicas promulgadas pela União e Estados. Posição essa que também se encontra na Lei da Política Nacional do Meio Ambiente, segundo a qual "Os Municípios, observadas as normas e os padróes federais e estaduais, também poderão elaborar as nomas mencionadas no parágrafo anterior" 38 .

No que tange à competência de implementação, territótio do poder de polícia, a Constituição atribuiu, de forma comum, à União, Estados, Distrito Federal e Municípios o dever-poder de "proteger o meio ambiente e combater a poluição em qualquer de suas formas" 39 e "preservar as florestas, a fauna e a flora" 40

Ao contrário do que se dá com a competência legislativa, os cidadãos, organizados ou não, dispõem igualmente de competência de implementação (via ação civil pública e ação popular, p. ex.).

\footnotetext{
33 Constituiçăo Federal, art. 24 , inciso VI.

${ }^{34}$ Constituição Federal, art. 24 , inciso VIII.

${ }^{35}$ Lei n. 6.938 , art. 6, par. 1.

${ }^{36}$ Constifuição Federal, art. 30, inciso 1.

${ }^{37}$ Constituiçăo Federal, art. 30, inciso II.

${ }^{38}$ Lei n. 6.938, art. 6, par. 2.

${ }^{39}$ Constituiçåo Federal, art. 23, inciso VI.

${ }^{40}$ Constituição Federal, art. 23, inciso VIt.
} 


\section{CONCLUSÄO}

O Brasil, afirma-se, tem hoje um dos mais avançados e completos sistemas de proteção legal do meio ambiente. Prioritário para o futuro (e para o presente), não mais é, no essencial, legislar. Já o fizemos. O que se espera agora dos órgãos ambientais e dos cidadãos, organizados ou não, é o cumprimento das exigências previstas, que, com freqüência, nada mais são do que letra morta. 